\title{
EVALUATION OF THE PROTECTIVE VALUE OF SOME TOXOCARA VITULORUM ANTIGENS IN RATS
}

\author{
By \\ OLFAT A. MAHDY*, WAHEED M. MOUSA, SAHAR Z. ABDEL-MAOGOOD \\ AND SHIMAA ABDEL-RADI
}

Department of Parasitology, Faculty of Veterinary Medicine, Cairo University, Giza, Egypt ( ${ }^{\star}$ Correspondence: E-mail: dr.olfat.mahdy@cu.edu.eg)

\section{Abstract}

Toxocara vitulorum is a nematode parasite of small intestine of buffalo, particularly young age calves, causing high morbidity and mortality. The control of this infection produces considerable economic benefits. Immunization of Wistar rats with different T. vitulorum antigens; (execratory/ secretory antigen (ESAg), peri-enteric fluid antigen (peAg) and embryonated eggs antigen (EEAg)) were evaluated for induction of protection against a challenge oral infection with embryonated eggs of $T$. vitulorum. It was found that peAg induce the highest protection level $(100 \%)$ followed by ESAg (96.4\%-97.5\%) then EEAg (93.7\%-96.7\%). Mean number of larvae extracted from immunized rats was significantly $(\mathrm{P} \leq 0.05)$ lower than that extracted from the control non-immunized one. The number of larvae collected after digestion of the liver at $3^{\text {rd }}$ day post challenge (dp.c.) was decreased from 998.5 in control rats to 26 and 41.5 in rats immunized with ESAg and EEAg respectively. In the same time no significant $(\mathrm{P} \leq 0.05)$ difference in size of larvae extracted from immunized and control positive rats. For conclusion, the study demonstrated the value of rats as experimental model for investigation $T$. vitulorum infection. It characterized PeAg as a valuable immunogenic and protective antigen in minimize the infection by $T$. vitulorum between mother and calves in infected farms.

Key words: Toxocara vitulorum, Rats, Experimental study, ELISA

\section{Introduction}

Toxocara vitulorum is a nematode parasite of small intestine of buffaloes, particularly young age calves, causing high morbidity and mortality. The larvae remain in the tissues of the infected dam until just prior to parturition then migrate to the mammary gland and milk for subsequent ingestion by the calf (Starke-Buzetti and Ferreira, 2006). Migration of the larvae through tissues produced severe inflammatory reactions and consequently to a wide range of pathological and clinical manifestations (Strube et al, 2013). The newly born calves were found to be highly infected at age of 15-90 days and consequently act as a source of infection to other animals in the farm as infected calves started to shed eggs at 16-23 days of age (Raza et al, 2013). The economic level and poor knowledge of farmers in tropical and sub- tropical countries which exposed to drink raw milk are likely to accelerate the transmission of the parasite causing larval migraines in human body (Rast et al, 2013).

Immunization trials with different $T$. vitulorum antigens using different experi- mental animals was investigated by some authors. Amerasinghe et al. (1992) reported that PeAg induced in mice $100 \%$ protection in comparison with ESAg which produce slight lower protection (82.6\%). Also vaccination of rabbits by EEAg decreased tissues invasion ability of larvae (El- Askalany et al, 2008).

With the presence of VLM infection in the Islamic Countries (low contact to dogs), T. vitullorum was considered as probable cause for the disease in human. Several studies are available on other Toxocara spp. causing VLM but some still under investigation for $T$. vitulorum such as its migratory pattern in both definitive and other hosts, duration of its larvae as inhibited larva in final hosts and the role of immunization in prevention of infection. Moreover, the buffaloes constitute one of the most important features of the Livestock as they occupy the prominent position among farm animals and play a great part in the national economy in Egypt. Several experimental animals, including Guinea-pigs (Buijs et al, 1993), rabbits (El-Askalany et al, 2008), mice (Cardillo et 
$a l, 2009)$, rats (El Kabany, 2013) and pigeons (Rahbar et al, 2013) in studying toxocariasis. But, the role of rats as experimental model for investigation of $T$. vitulorum infection was neglected in comparison to other laboratory animals (Strub et al, 2013).

This study aimed to investigate the efficacy of vaccination by different $T$. vitulorum antigens in animal protection from infection using rats as a model for the present study to demonstrate its value in investigation of $T$. vitulorum infection.

\section{Materials and Methods}

All the study steps and procedures were approved by the Institutional Animal Care and Use Ethical Committee (CU-IACUC) of Cairo University (CU/ II/ S/ 2016/ 2017).

Antigens of $T$. vitulorum: Intact, active $T$. vitulorum adult worms were collected from intestine of freshly slaughtered buffalo calves in Cairo abattoir, Egypt. The worms were washed in normal saline then used for preparation of ESAg and peAg while $T$. vitulorum eggs were collected from the distal part of the uteri of the adult female worms and then embryonated (Starke and Ferreira, 2006) to be used to prepare EEAg and induction of infection of rats.

Adult $T$. vitulorum ESAg: The ESAg was collected after incubation of both adult active male and female $T$. vitulorum at $37^{\circ} \mathrm{C}$ for $2 \mathrm{hrs}$ in PBS supplemented with antibiotic (Amerasinghe et al, 1992). Then the fluid was centrifuged at $460 \mathrm{xg}$ for 5 minutes and the supernatant was filtered. Protein content was increased by concentration using polyethylene glycol in molecular porous membrane tubing 6-8 MW cut off (Spectrum Medical Inc., Los Angeles, CA 900060) at $4^{\circ} \mathrm{C}$ (Goswami et al, 2013). The concentrated fluid was collected and its protein content was measured using Lowry's Assay (1951) then stored at $-20^{\circ} \mathrm{C}$ till use.

Adult T. vitulorum PeAg: The PeAg was collected from adult active $T$. vitulorum by puncturing the posterior end of each parasite with needle and perienteric fluid was drained, collected and centrifuged at 460xg for 5 minutes then treated as ESAg (Ferreira and Starke-Buzetti, 2005).

Toxocara vitulorum EEAg: The EEAg was prepared from the previous embryonated $T$. vitulorum eggs after several washing with 0.01 PBS (PH 7.4) by centrifugation at 1500 r.p.m. for 3 minutes. The sedimented eggs were mixed with an equal volume of the same solution then homogenized at 6000 r.p.m for 5 minutes in an ice bath. The homogenized sample was sonicated for 5 minutes at 5 pulse rate and 60-80 amplitude value using Coleparmer Ultrasonic homogenizer then suspension was subjected to high speed centrifugation at $14,000 \mathrm{rpm}$ for 30 minutes at $4^{\circ} \mathrm{C}$ and the supernatant was separated as EEAg, concentrated and its protein contents was measured and stored as before (El- Askalany et al, 2008).

Experimental study: Sixty (60) Male Wistar white rats of 120-200 gram were divided into 4 groups; GA: (immunized T. vitulorum group) 30 rats were immunized with different $T$. vitulorum antigen (ten rats for each type of antigen), GB: (control positive $T$. vitulorum group) ten non immunized rats infected with embryonated $T$. vitulorum eggs at time of challenge infection, GC: (adjuvant control group) ten rats were injected with adjuvant alone and GD: (control negative group) ten non immunized rats kept non infected throughout the experimental study.

Immunization protocol: According to the method given by Tang et al. (2015) with little modification, the prepared $T$. vitulorum antigens (ESAg, PeAg \& EEAg) were used to produce hyperimmune sera. Sera were collected before immunization as negative sera. Rats were immunized subcutaneously with $1.2 \mathrm{mg}$ protein of $T$. vitulorum antigens, emulsified 1:1 with mineral oil. After 2 weeks another $1.2 \mathrm{mg}$ protein was mixed 1:1 in oil and divided into 3 doses (day 14, 21 \& 28) then injected subcutaneously. One week after the last immunization; Rats were bled for serum collection and the level of antibodies was measured. The collected sera were stored at $-20^{\circ} \mathrm{C}$ until used as positive 
Optical densities (O.D) were read at 450nm with a micro-ELISA reader system. The sera were considered positive when absorbance values were as or more than the cut off value that double fold of the mean negative control sera.

Statistical analysis: Data were computerized and analyzed by the statistical package SSPS by using Chi-square test. The differences were expressed as significant at $\mathrm{P} \leq$ 0.05 (Verzani, 2004).

\section{Results}

Immunization of rats by different $T$. vitulorum antigens showed marked reduction in the total mean number of larvae extracted from tissue of immunized rats as compared to control non-immunized groups with differences related to antigen type used (Tab. $2)$. The mean number of extracted larvae decreased from 998.5 at $3^{\text {rd }}$ p.i. to 87 at $45^{\text {th }}$ dp.i. during migration from liver to muscles in control positive group, from 983 to 79 in adjuvant group, from 26 to 3 in group immunized by ESAg and from 41.5 to 7 in the group immunized by EEAg in same period between liver and muscles respectively.

After oral inoculation of (GB \& GC) with T. vitulorum embryonated eggs (Tab. 3 ), the highest number of larvae was in rats' liver sacrificed at 3 dp.i., extracted from different organs except muscles at $7^{\text {th }}$ dp.i. with high number in lung. While at $15^{\text {th }}$ dp.i., larvae were extracted from different organs include ing muscles till the study end with progress sive decreasing number of larvae. The same pattern was detected in the immunized rats after challenge with $T$. vitulorum embryonated eggs at 3 dp.c., but larvae were extracted only from liver, lung and spleen at $7^{\text {th }}$ dp.c. in ESAg immunized rats. While in EEAg immunized rats, larvae also extracted from the kidney.

At $15^{\text {th }}$ dp.c., larvae were extracted only from liver of ESAg immunized rats till the study end. Few numbers of larvae were extracted from liver, lung, spleen and muscles of EEAg immunized rats at $30^{\text {th }}$ dp.c. \& $45^{\text {th }}$ dp.c., but only detected in liver.

In the present study, immunized rats by different antigens as compared to control positive rats after infection challenge (Tab. 4) showed $100 \%$ protection in rats immunized with PeAg followed by ESAg (96.497.5\%), lowest was in the EEAg immunized rats $(93.7-96.7 \%)$. The results showed no significant difference in size of extracted larvae from control positive or immunized rats. Mean size of larvae from control positive group was (391.6 $\pm 8 \times 18.4 \pm 2.1)$, (399.8 $\pm 16 x$ $18.8 \pm 2.3), \quad(413.5 \pm 11 \times 19.6 \pm 2.6), \quad(418 \pm 18 x$ $18.2 \pm 3.1) \&(419.3 \pm 10 x 19.4 \pm 2.9)$ from liver, lung, spleen, kidney and brain respectively, as corresponded with (360-440x15-18), (360-459x16-20) and (366-468x 16-20) from liver, lung and spleen of rats immunized by ESAg respectively and (362-442x16-18), (362-461x16-20), (369-462x17-20) and (368-460x17-20) from liver, lungs, spleen and kidney of EEAg immunized rats respectively. Scan Electron Microscope showed no differences in morphology between the extracted larvae from the rat' groups. T. vitulorum larvae appeared small cylindrical with a rather narrow anterior extremity. It was ensheathed in a loose cuticle that forms several wrinkles, particularly at the cervical region. The mouth opening is roughly circular to triangular. It lies on the top of the cephalic plate, and is surrounded with six massive and ill-defined lips. In some larvae, the cuticular incisions separating these lips are not deep (Fig. 2).

Table 2: Total mean No. of $T$. vitulorum larvae extracted from sacrificed rats at different days post infection \& post challenge

\begin{tabular}{|c|c|c|c|c|}
\hline \multirow{2}{*}{$\begin{array}{c}\text { Time of slaugh- } \\
\text { tering }\end{array}$} & \multicolumn{4}{|c|}{ Total mean number of T. vitulorum larvae extracted from } \\
\cline { 2 - 5 } & GA ESAg & GA EEAg & GB & GC \\
\hline 3 dp.i./p.c. & 26 & 41.5 & 998.5 & 983 \\
\hline 7 dp.i./ p.c. & 22 & 29.5 & 887 & 880 \\
\hline 15 dp.i/ p.c. & 11 & 18.5 & 300.5 & 280 \\
\hline 30 dp.i/ p.c. & 5.5 & 9.5 & 150.5 & 123.5 \\
\hline 45 dp.i./ p.c. & 3 & 7 & 87 & 79 \\
\hline
\end{tabular}


Table 3: Mean No. of $T$. vitulorum larvae extracted from 2 sacrificed rats' organs at different days post infection \& post challenge.

\begin{tabular}{|c|c|c|c|c|c|c|}
\hline \multirow{2}{*}{ Examined organs } & \multirow{2}{*}{$\begin{array}{l}\text { Antigen used in } \\
\text { immunization }\end{array}$} & \multicolumn{5}{|c|}{ Larvae mean number at different days post infection or post challenge } \\
\hline & & 3 & 7 & 15 & 30 & 45 \\
\hline \multirow{3}{*}{ Liver } & ESAg & 26 & 14.5 & 11 & 5.5 & 3 \\
\hline & $\mathrm{PeAg}$ & 0 & 0 & 0 & 0 & 0 \\
\hline & EEAg & 41.5 & 12 & 9 & 9.5 & 7 \\
\hline \multicolumn{2}{|c|}{ No. of larvae in control positive rats } & 998.5 & 328 & 103.5 & 39.5 & 12 \\
\hline \multicolumn{2}{|c|}{ No. of larvae in adjuvant group } & 983 & 311.5 & 89 & 26 & 8.5 \\
\hline \multirow{3}{*}{ Lung } & ESAg & 0 & 5 & 0 & 0 & 0 \\
\hline & $\mathrm{PeAg}$ & 0 & 0 & 0 & 0 & 0 \\
\hline & EEAg & 0 & 10 & 5.5 & 0 & 0 \\
\hline \multicolumn{2}{|c|}{ No. of larvae in control positive rats } & 0 & 512 & 126 & 47 & 16.5 \\
\hline \multicolumn{2}{|c|}{ No. of larvae in adjuvant group } & 0 & 523 & 121.5 & 39 & 10 \\
\hline \multirow{3}{*}{ Spleen } & ESAg & 0 & 2.5 & 0 & 0 & 0 \\
\hline & PeAg & 0 & 0 & 0 & 0 & 0 \\
\hline & EEAg & 0 & 4.5 & 2 & 0 & 0 \\
\hline \multicolumn{2}{|c|}{ No. of larvae in control positive rats } & 0 & 13 & 26 & 9.5 & 4 \\
\hline \multicolumn{2}{|c|}{ No. of larvae in adjuvant group } & 0 & 16 & 27.5 & 7 & 3.5 \\
\hline \multirow{3}{*}{ Kidney } & ESAg & 0 & 0 & 0 & 0 & 0 \\
\hline & $\mathrm{PeAg}$ & 0 & 0 & 0 & 0 & 0 \\
\hline & EEAg & 0 & 3 & 0 & 0 & 0 \\
\hline \multicolumn{2}{|c|}{ No. of larvae in control positive rats } & 0 & 26 & 14 & 5 & 0 \\
\hline \multicolumn{2}{|c|}{ No. of larvae in adjuvant group } & 0 & 23.5 & 11 & 3.5 & 0 \\
\hline \multirow{3}{*}{ Brain } & ESAg & 0 & 0 & 0 & 0 & 0 \\
\hline & $\mathrm{PeAg}$ & 0 & 0 & 0 & 0 & 0 \\
\hline & EEAg & 0 & 0 & 0 & 0 & 0 \\
\hline \multicolumn{2}{|c|}{ No. of larvae in control positive rats } & 0 & 8 & 12 & 13.5 & 3.5 \\
\hline \multicolumn{2}{|c|}{ No. of larvae in adjuvant group } & 0 & 6 & 11 & 11.5 & 3 \\
\hline \multirow{3}{*}{ Muscles } & ESAg & 0 & 0 & 0 & 0 & 0 \\
\hline & PeAg & 0 & 0 & 0 & 0 & 0 \\
\hline & EEAg & 0 & 0 & 2 & 0 & 0 \\
\hline \multicolumn{2}{|c|}{ No. of larvae in control positive rats } & 0 & 0 & 19 & 36 & 51 \\
\hline \multicolumn{2}{|c|}{ No. of larvae in adjuvant group } & 0 & 0 & 20 & 36.5 & 54 \\
\hline
\end{tabular}

Table 4: Level of protection induced by T. vitulorum antigens in immunized rats at different days post challenge.

\begin{tabular}{|c|c|c|c|c|c|c|c|}
\hline \multirow[b]{3}{*}{$\begin{array}{c}\text { Time of } \\
\text { slaughtering }\end{array}$} & \multirow{3}{*}{$\begin{array}{c}\text { Total mean No. } \\
\text { of extracted } \\
\text { control +ve } \\
\text { larvae }\end{array}$} & \multicolumn{6}{|c|}{$\%$ of protection after immunization with } \\
\hline & & \multicolumn{2}{|c|}{ ESAg } & \multicolumn{2}{|c|}{$\mathrm{PeAg}$} & \multicolumn{2}{|l|}{ EEAg } \\
\hline & & $\begin{array}{c}\text { Total mean No. } \\
\text { of extracted } \\
\text { larvae }\end{array}$ & $\begin{array}{c}\% \text { of } \\
\text { protection }\end{array}$ & $\begin{array}{c}\text { Total mean No. } \\
\text { of extracted } \\
\text { larvae }\end{array}$ & $\begin{array}{c}\% \text { of } \\
\text { protection }\end{array}$ & $\begin{array}{l}\text { Total mean No. of } \\
\text { extracted larvae }\end{array}$ & $\begin{array}{c}\% \text { of } \\
\text { protection }\end{array}$ \\
\hline 3 dp.c. & 998.5 & 26 & 97.4 & 0 & \multirow{5}{*}{100} & 41.5 & 95.8 \\
\hline 7 dp.c. & 887 & 22 & 97.5 & 0 & & 29.5 & 96.7 \\
\hline 15 dp.c. & 300.5 & 11 & 96.4 & 0 & & 18.5 & 93.8 \\
\hline 30 dp.c. & 150.5 & 5.5 & 96.4 & 0 & & 9.5 & 93.7 \\
\hline 45 dp.c. & 87 & 3 & 96.6 & 0 & & 7 & 95.9 \\
\hline
\end{tabular}

Table 5: Size variations in 7 days old larvae extracted from immunized and control positive rats.

\begin{tabular}{|c|c|c|c|c|c|c|}
\hline \multirow[b]{2}{*}{ Organs } & \multicolumn{6}{|c|}{ Larvae extracted from } \\
\hline & \multicolumn{2}{|c|}{ ESAg immunized group } & \multicolumn{2}{|c|}{ EEAg immunized group } & \multicolumn{2}{|c|}{ Control positive group } \\
\hline Liver & $360-440 \times 15-18$ & $385.7 \pm 12 \times 16.8 \pm 0.7$ & $362-442 \times 16-18$ & $386.2 \pm 12 \times 17.2 \pm 1.4$ & $367-446 \times 16-20$ & $391.6 \pm 8 \times 18.4 \pm 2.1$ \\
\hline Spleen & $366-468 \times 16-20$ & $411.3 \pm 10 \times 18 \pm 1.8$ & $369-462 \times 17-20$ & $408.6 \pm 9 \times 18.3 \pm 1.8$ & $371-469 \times 18-22$ & $413.5 \pm 11 \times 19.6 \pm 2.6$ \\
\hline Kidney & -- & -- & $368-460 \times 17-20$ & $414.3 \pm 9 \times 18 \pm 2$ & $370-468 \times 17-22$ & $418 \pm 18 \times 18.2 \pm 3.1$ \\
\hline Brain & -- & -- & -- & -- & $373-468 \times 18-22$ & $419 . \pm 10 \times 19.4 \pm 2.9$ \\
\hline
\end{tabular}

Changes in level of anti-T. vitulorum antibodies (ATv-Ab) after challenge and infection of different rat groups: Immunization of rats by the 3 tested $T$. vitulorum antigens revealed high $\mathrm{Ab}$ titre at the end of immunization period $\left(35^{\text {th }}\right.$ dp.im.) with marked superiority to $\mathrm{PeAg}$ as the best immunogenic type (mean OD was 0.923 ) followed by the ESAg (0.862) and the lowest level of produced $\mathrm{Ab}$ level was in the EEAg immunized group (0.728) as compared with the ELISA OD value of each rat at day zero of immunization trial and with adjuvant group.

The challenge of each rat with 10, 000 embryonated eggs revealed gradual increase in the level of antibodies in all of immunized groups till the period end $\left(45^{\text {th }}\right.$ dp.c.). The recorded levels of antibodies in each time still related to the primary level of antibodies produced from each $\mathrm{Ag}$ before challenge. 
In this respect, $\mathrm{Ab}$ level in the group immunized by PeAg still that have the highest level of $A b$ in their post challenge sera. It was noticed that the pattern of changes in $\mathrm{ATV}-\mathrm{Ab}$ titre in control positive rats differed than that in immunized rats as it increased gradually from 0.176 at $3^{\text {rd }}$ dp.i. to 0.547 at 45 d.pi. This rate of gradual increase in control positive rats was higher than that in the adjuvant group (Tab. 6 \& Fig. 3).

Table 6: Changes in the level of ATv-Ab in immunized and control rats post challenge \& infection.

\begin{tabular}{|l|c|c|c|c|c|c|}
\hline \multirow{2}{*}{$\begin{array}{c}\text { Time of Ab level } \\
\text { determination }\end{array}$} & \multicolumn{2}{|c|}{ Changes in Ab titter in (GA immunized by } & \multicolumn{3}{|c|}{ Changes in Ab titter in controls } \\
\cline { 2 - 7 } & ESAg & PeAg & EEAg & (GB) & (GC) & $(\mathrm{GD})$ \\
\hline Zero day & 0.141 & 0.148 & 0.152 & 0.154 & 0.138 & 0.125 \\
\hline 35 dp.im. & 0.862 & 0.923 & 0.728 & 0.147 & 0.304 & 0.129 \\
\hline 3 dp.i./p.c. & 0.592 & 0.719 & 0.509 & 0.176 & 0.263 & 0.167 \\
\hline 7 dp.i./p.c. & 0.634 & 0.782 & 0.593 & 0.288 & 0.281 & 0.181 \\
\hline 15 dp.i/ p.c. & 0.678 & 0.881 & 0.613 & 0.480 & 0.411 & 0.154 \\
\hline 30 dp.i/ p.c. & 0.776 & 0.914 & 0.661 & 0.502 & 0.456 & 0.130 \\
\hline 45 dp.i./ p.c. & 0.839 & 0.958 & 0.689 & 0.547 & 0.489 & 0.143 \\
\hline
\end{tabular}

\section{Discussion}

Toxocara vitulorum infection is an important cause of losses in buffaloes and calves whose economic importance cannot be neglected. Moreover, it considered as a probable cause for VLM in Egyptian people as they are of low contact to dogs. For these reasons the present study aimed to investigate the efficacy of vaccination by different T. vitulorum antigens as a way for protection from infection by this parasite.

In the present study, rats' infection with $T$. vitulorum embryonated eggs revealed appearance of high number of larvae in liver at 3 dp.i. and then the larvae spread to the rest of tissues at $7^{\text {th }}$ dp.i. with high number in the lung. While the larvae extracted from the previouse organs and muscles at $15^{\text {th }}$ d.p.i. and still diagnose in these organs till the end of the experiment. This migratory pattern matched with Omar and Barriga (1991) who reported that the larvae found in the highest number in liver at first days p.i then spread to the rest of tissues with decreasing number. Alsom the results agreed with Strube $e t$ al. (2013) who described the migratory pattern in different paratenic hosts and also mentioned that $T$. vitulorum larvae had low affinity to the brain.

In the present study, it was found that immunization by $\mathrm{PeAg}$ showed $100 \%$ protection versus challenge infection, followed by the ESAg (96.4-97.5\%) and EEAg (93.7$96.7 \%$ ). This reflects the migratory behavior of $T$. vitulorum larvae in the immunized rats as the number of larvae extracted from those rats was lower than that extracted from the control positive rats. This result agreed with Amerasinghe et al. (1992) found that peAg was most protective antigen against $T$. vitulorum infection in mice followed by ESAg. El-Askalany et al. (2008) reported that immunization of rabbits with EEAg decreased the tissue invasion with larvae. Omar and Barriga (1991) explained that the decrease in number of the extracted larvae may be due to intestinal resistance which inhibited hatching and prevention of larvae from mucosal penetration. Even if some embryonated eggs were hatched; the larvae might be killed by the action of tissue defense mechanism (macrophages), or by the action of the eosinophilic degranulation, Capron (1991). While Ruppel et al. (1990) reflected the decrease in number due to reduction in the rate of migration of the larvae to the tissues and killing some of the parasites during the first 3 weeks of infection.

In the present study, PeAg showed the most immunogenic $T$. vitulorum antigen causing high Ab-titre at $35^{\text {th }}$ dp.im. followed by ESAg and the lowest level was in group immunized by EEAg using ELISA. These results were confirmed by the data obtained after postmortem examination, as immunization by PeAg produced the highest protection level. It was noticed that the level of antibodies in the immunized rats' sera after 
the challenge with $T$. vitulorum embryonated eggs was higher than that in the other infected rats. High positive antibodies titer was noticed at 15 dp.i./ p.c. and remained high during the experimental period until day 45, which agreed with Morales et al. (2002) who detected an increase in the level of antibodies 2 weeks post T. canis infection of rabbits till the end of the experimental study.

In the present study, there was a significant $(\mathrm{P} \leq 0.05)$ decrease in the number of the extracted larvae from immunized rats than that extracted from other infected rats, there was non-significant decrease in the size of extracted larvae at $7^{\text {th }}$ dp.i/ p.c. from rats in both immunized and control groups. This result agreed with Barriga and Omar (1992) who reported that the size of $T$. vitulorum larvae in the tissues of the infected nonimmunized rabbits increased with the time. Moreover, Warren (1971) reported that even the larvae survived and invaded tissues of immunized rabbits, their growth may be retained. In the same time, SEM investigation determined absence of any morphological alternation in the structure of larvae extracted from immunized and control rats.

It was worthy to mention that the $7^{\text {th }} \mathrm{dp.i} /$ p.c. was selected as a time for evaluating the size of the extracted larvae aiming to investigate the effect of immunization only on the migrating larvae, as with increasing the time post infection, some other factors may affect the size of the produced larvae such as migration of the larvae through un-proper way or away from good nourished organs. So selection of this time avoids the possibility of the effect of other factors that may inhibit larval development other than immunestatus of the animal.

It was noticed that $T$. vitulorum infection in rats in the adjuvant group had the same pattern of rats in the infected non-immunized group throughout the study. This proved that the reported high Ab levels and immunization effect was produced only by the action of the injected antigens not the adjuvant.
In the present study, effect of immunization on the invading larvae was inspected from two main aspects, the first one was its effect on number of larvae succeeded to penetrate the intestinal wall of immunized rats, while the second one was focused on the effect of immunization on the morphological features of the penetrating larvae from the aspect of its size and structures. Immunization caused significant $(\mathrm{P} \leq 0.05)$ decrease in the number of penetrating larvae but it did not affect the size till 7 dp.i. Besides, inspection of larvae using light and SEM examination revealed no morphological changes were detected in the extracted larvae from immunized rats in comparison with that extracted from non-immunized rats after the infection. T. vitulorum morph-ology by SEM went with Ashour et al. (1996).

Immunization of rats succeeded to build an early line of defense on the intestinal wall. These diminished the ability of most invading larvae to induce successful penetration to intestinal wall and arrive to general circulation. In the same time, effect of immunization on larvae after this appear lower than this effect as the larvae that succeed in penetration to intestinal wall reached to different body organs.

\section{Conclusion}

The results revealed that the migratory pattern and vaccination trials for $T$. vitulorum infection in rats showed close results of that studied in other paratenic hosts. Therefore we concluded that rats can be considered as a suitable model for performing some investigations of $T$. vitulorum infection in the suspected hosts and even testing the efficacy of some control methods rather than treatments.

Moreover, the PeAg was considered to be valuable immunogenic and protective antigen, can used in minimize infection by $T$. vitulorum between mothers and calves by vaccination in infected farms.

\section{References}

Amerasinghe, PH, Rajapakse, RPVJ, Lloyd, S, Fernando, ST, 1992: Antigen-induced pro- 
tection against infection with $T$. vitulorum larvae in mice. Parasitol. Res. 78:643-7.

Ashour, AA, Wanas, MQ, Omar, HM, 1996: Scanning electron microscopy of the egg and the second stage larva of T. vitulorum. Qatar Univ. Sci. J. 16, 2:303-5.

Barriga, OO, Omar, MH, 1992: Immunity to T. vitulorum repeated infection in a rabbit model. Vet. Immunol. Immunopathol. 33:249-60.

Buijs, J, Egbers, MW, Nijkamp, FP, 1993: Toxocara canis induced airway eosinophilia and tracheal hyporeactivity in guinea pigs and mice. Eur. J. Pharmacol. 293:207-15.

Capron, M, 1991: Eosinophils and parasites. Ann. Parasital. Hum. Comp. 66, 1:41-5.

Cardillo, N, Rosa, A, Ribicich, M, Lopez, C, Sommerfelt, I, 2009: Experimental infection with $T$. cati in BALB/c mice, migratory behavior and pathological changes. Zoonosis Publ. Hlth. 56:98-105.

Davila, G, Irsik, M, Greiner, EC, 2010: Toxocara vitulorum in beef calves in North Central Florida. Vet. Parasitol. 168:261-3.

El-Askalany, MA, Mousa, WM, Abo-El Hadid, SM, Lotfy, HS, 2008: Immune characterization of T. canis embryonated egg antigen in experimentally infected rabbits. Egypt. J. Exp. Biol. 4:31-7.

El-Kabany, H, 2013: Biochemical and histopathological studies on liver of rats infected with non-irradiated and/or Irradiated $T$. vitulorum eggs. J. Rad. Res. Appl. Sci. 6, 1:137-54.

Ferreira, FP, Starke-Buzetti, WA, 2005: Detection of antibody to T. vitulorum perieneteric fluid antigens $(\mathrm{Pe})$ in the colostrum and serum of buffalo calves and cows by Western blotting. Vet. Parasitol. 129:119-24.

Goswami, A, Das, D, Laha, R, 2013: Characterization of immunogenic proteins of Cysticercus tenuicollis of goats. Vet. Wld. 6, 5:267-70.

Liu, P, Cui, J, Liu, RD, Wang, M, Jiang, P, et al, 2015: Protective immunity against Trichinella spiralis infection induced by $\mathrm{TsNd}$ vaccine in mice. Parasites Vectors 180:185-92.

Lowry, OH, Rosebrough, NJ, Farr, AL, Randall, RJ, 1951: Protein measurements with folin phenol reagent. J. Bioi. Chern. 193: 265-75.

\section{Explanation of figures}

Fig. 1: a T. vitulorum larva extracted from control positive rat, b: T. vitulorum larva extracted from ESAg immunized rat, c: T. vitulorum larva extracted from EEAg immunized rat

Fig. 2: Morphology of extracted larvae by SEM.

Fig. 3: Changes in Ab level in immunized and control rats post challenge or infection.
Morales, O L, Lopez, M C, Nicholls, R S, Agudelo, C, 2002: Identification of $T$. canis antigens by Western blot in experimentally infected rabbits. Rev. Inst. Med. Trop. S. Paulo. 44, 4: 213-6.

Omar, MH, Barriga, OO, 1991: Biology and pathophysiology of $T$. vitulorum infection in a rabbit model. Vet. Parasitol. 40:257-66.

Rast, L, Lee, S, Nampanya, S, Toribio, JA, Khounsy, S, et al, 2013: Prevalence and clinical impact of $T$. vitulorum in cattle and buffalo calves in northern Lao PDR. Trop. Anim. Hlth. Prod. 45:539-46.

Raza, MA, Ayaz, MM, Murtaza, S, Akhtar, MS, Arshad, HM, et al, 2013: Toxocara vitulorum infestation and associated risk factors in cattle and buffalo at Multan district, Pakistan. Sci. Int. 25, 2:291-4.

Rahbar, A, Alborzi, A, Seifi, M, 2013: An alternative method for producing $T$. canis second stage larvae from a paratenic host (pigeon) for mRNA extraction purpose. J. Parasit. Dis. 39, 2: 186-9.

Ruppel, A, Shi, YE, Moloney, NA, 1990: Schiistosoma mansoni and Schistosoma japonicum: Comparison of levels of Ultraviolet radiation for vaccination of mice with cercaria. Parasit. 3: 101-8.

Starke-Buzetti, WA, Ferreira, FP, 2006: Characterization of excretory/secretory antigen from T. vitulorum Larvae. Ann. N.Y. Acad. Sci. 1026: 210-8.

Strub, C, Heuer, L, Janecek, E, 2013: Toxocara spp. infections in paratenic hosts. Vet. Parasitol. 193:375-89.

Tang, B, Liu, M, Wang, L, 2015: Characterization of a high-frequency gene encoding a strongly antigenic cystatin-like protein from Trichinella spiralis at its early invasion stage. Parasites Vectors 8:78-82.

Verzani, J, 2004: Introductory Statistics; Chapman and Hall/CRC Publishing.

Warren, EG, 1971: Observation on migration and development of $T$. vitulorum in natural and experimental hosts. Int. J. Parasitol. 1:85-96. 

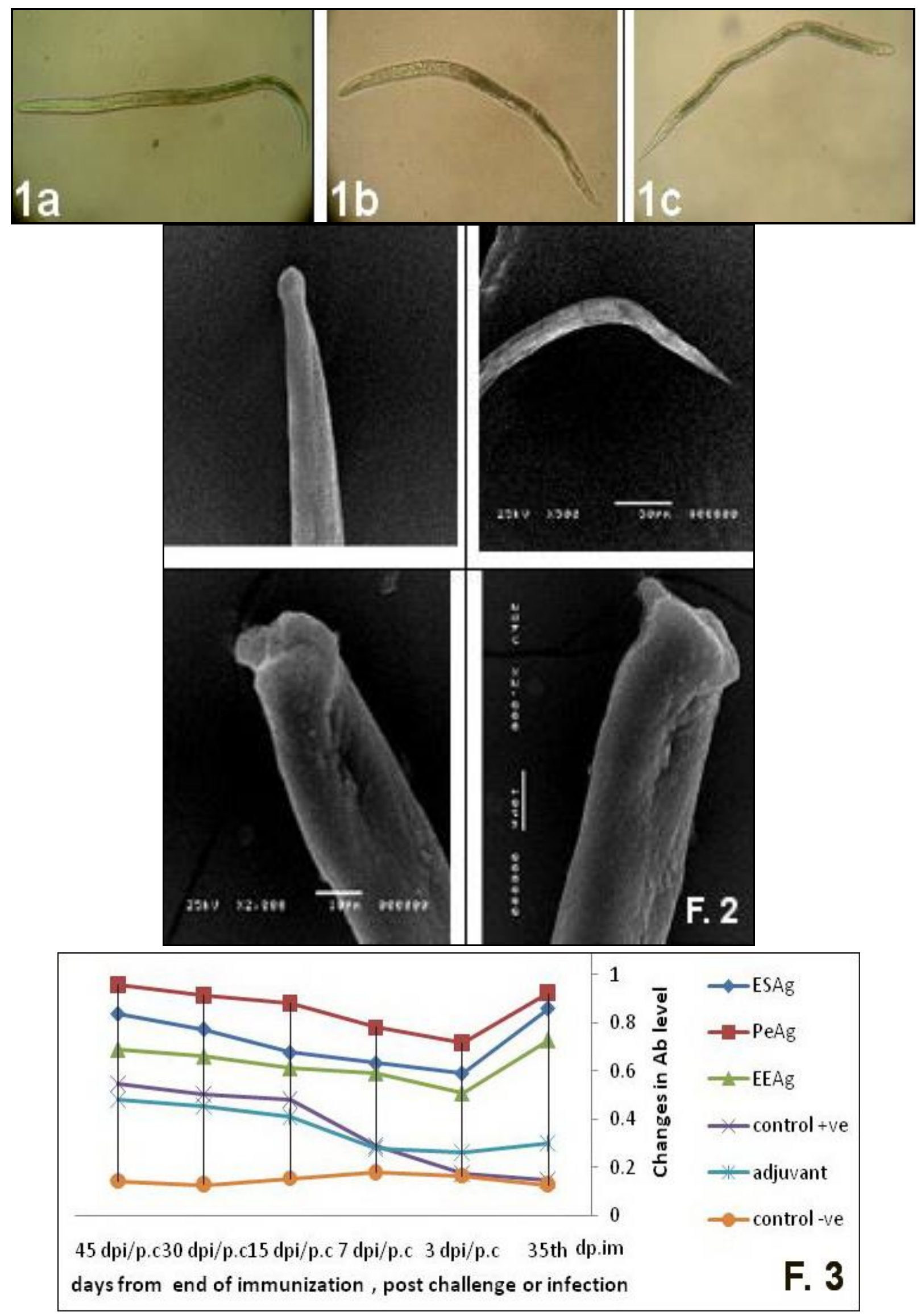